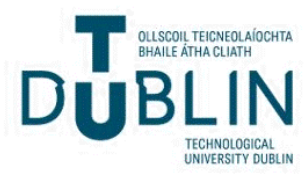

Technological University Dublin

ARROW@TU Dublin

Articles

School of Food Science and Environmental

Health

2017-06-26

\section{Ferric Chloride Assisted Plasma Pretreatment of Lignocellulose}

\author{
Rajeev Ravindran \\ Technological University Dublin \\ Chaitanya Sarangapani \\ Technological University Dublin, chaitanyakrishna.sarangapani@tudublin.ie \\ Swarna Jaiswal \\ Technological University Dublin, swarna.jaiswal@tudublin.ie
}

See next page for additional authors

Follow this and additional works at: https://arrow.tudublin.ie/schfsehart

Part of the Bioresource and Agricultural Engineering Commons

\section{Recommended Citation}

Ravindran, R., et al. (2017) Ferric chloride assisted plasma pretreatment of lignocellulose, Bioresource Technology (2017), doi: http://dx.doi.org/10.1016/j.biortech.2017.06.123

This Article is brought to you for free and open access by the School of Food Science and Environmental Health at ARROW@TU Dublin. It has been accepted for inclusion in Articles by an authorized administrator of ARROW@TU Dublin. For more information, please contact arrow.admin@tudublin.ie, aisling.coyne@tudublin.ie, gerard.connolly@tudublin.ie.

Funder: Technological University Dublin (DIT), Dublin, Ireland

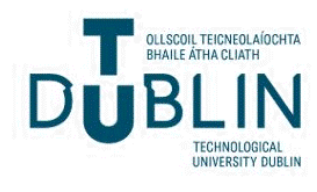




\section{Authors}

Rajeev Ravindran, Chaitanya Sarangapani, Swarna Jaiswal, Patrick Cullen, and Amit Jaiswal 


\section{Accepted Manuscript}

Ferric chloride assisted plasma pretreatment of lignocellulose

Rajeev Ravindran, Chaitanya Sarangapani, Swarna Jaiswal, P.J. Cullen, Amit K. Jaiswal

PII: S0960-8524(17)31027-1

DOI: http://dx.doi.org/10.1016/j.biortech.2017.06.123

Reference: BITE 18360

To appear in:

Bioresource Technology

Received Date: $\quad 25$ April 2017

Revised Date: $\quad 21$ June 2017

Accepted Date: $\quad 22$ June 2017

Please cite this article as: Ravindran, R., Sarangapani, C., Jaiswal, S., Cullen, P.J., Jaiswal, A.K., Ferric chloride assisted plasma pretreatment of lignocellulose, Bioresource Technology (2017), doi: http://dx.doi.org/10.1016/ j.biortech.2017.06.123

This is a PDF file of an unedited manuscript that has been accepted for publication. As a service to our customers we are providing this early version of the manuscript. The manuscript will undergo copyediting, typesetting, and review of the resulting proof before it is published in its final form. Please note that during the production process errors may be discovered which could affect the content, and all legal disclaimers that apply to the journal pertain. 
1 Ferric chloride assisted plasma pretreatment of lignocellulose

3 Rajeev Ravindran ${ }^{1}$, Chaitanya Sarangapani ${ }^{1}$, Swarna Jaiswal ${ }^{2}$, P. J. Cullen ${ }^{1}$, Amit K. $4 \quad$ Jaiswal $^{1 *}$

$6{ }^{1}$ School of Food Science and Environmental Health, College of Sciences and Health, Dublin 7 Institute of Technology, Cathal Brugha Street, Dublin 1, Republic of Ireland.

$8{ }^{2}$ Centre for Research in Engineering and Surface Technology, FOCAS Institute, Dublin Institute 9 of Technology, Kevin Street, Dublin 8, Republic of Ireland.

14 *Corresponding author

16 Email: amit.jaiswal@dit.ie; akjaiswal@ outlook.com

17 Tel: +35314024547 


\section{Abstract}

23 In this study, a novel pretreatment for spent coffee waste (SCW) has been proposed which

24 combines two techniques viz. atmospheric air plasma and $\mathrm{FeCl}_{3}$ to create a superior pretreatment

25 that involves Fenton chemistry. The pretreatment was optimised employing Taguchi Design of

26 Experiments, and five parameters were taken into consideration viz. biomass loading, $\mathrm{FeCl}_{3}$

27 concentration, $\mathrm{H}_{2} \mathrm{SO}_{4}$ concentration, plasma discharge voltage and treatment time. The

28 composition analysis of the pretreated SCW revealed substantial amounts of lignin removal, with

29 a maximum for process conditions of $70 \mathrm{kV}$ for $2 \mathrm{~min}$ in an acidic environment containing $1 \%$

$30 \mathrm{H}_{2} \mathrm{SO}_{4}$. FTIR, XRD and DSC were performed to characterise the samples. The pretreated SCW

31 after enzymatic hydrolysis yielded $0.496 \mathrm{~g}$ of reducing sugar/g of SCW. The hydrolysate was

32 subjected to fermentation by $S$. cerevisiae and led to the production of $18.642 \mathrm{~g} / 1$ of ethanol with

33 a fermentation efficiency of $74 \%$, which was a two-fold increase in yield compared to the

34 control.

37 Keywords: Lignocellulose; biomass pretreatment; spent coffee waste; cold air pressure plasma;

38 Fenton reaction; bioethanol production 


\section{Introduction}

46 With petroleum resources dwindling, the world has a renewed interest in sustainable sources of

47 energy such as bioethanol. Lignocellulose is one the most abundant renewable resources in the

48 world. In recent years, lignocellulosic plant wastes from various industry sectors such as food

49 and agriculture have widely been researched as potential substrates for bioethanol production.

50 Spent coffee waste (SCW) is the solid material obtained after brewing of instant coffee and is a

51 rich source of lignocellulose. Over the past few years' global coffee production and consumption

52 has been on the rise. Coffee is one of the most popular beverages in the world, with global coffee

53 production reaching 8.5 billion tonnes in 2015/2016 (ICO, 2016).

54 Lignocellulose is a complex polymer of polysaccharides and lignin. In nature, plant cell wall can

55 naturally resist degradation by microbial, enzymatic and chemical attack. Consequently, the

56 efficient utilisation of polysaccharides is challenging. This calls for suitable methods that can

57 remove recalcitrance of lignocellulose. Pretreatment of lignocellulosic biomass are necessary to

58 disrupt the lignocellulosic complex to expose cellulose to enzymatic hydrolysis (Ravindran \&

59 Jaiswal, 2016a). Numerous studies have reported on pretreatment methods and their efficacies

60 over the past few decades. Some of the most effective pretreatment methods that offer

61 commercial feasibility include steam explosion, dilute acid pretreatment and ammonia fibre

62 expansion (Campbell et al., 2013; Rocha et al., 2015). Recently, treatment with ferric chloride

63 was investigated as a feasible pretreatment measure for bagasse, rice straw and wood fibre by

64 Chen et al. (2015). Studies involving plasma generated ozone for delignification of wheat straw

65 and subsequent bioethanol production was studied by Schultz-Jensen et al., (2011). 
66 Several pretreatment methods have been devised for lignocellulose over the past decade.

67 However, very few studies have focused the effective pretreatment of SCW. For example,

68 characterisation of polysaccharides extracted from alkali pretreated SCW was performed by

69 Ballesteros et al., (2015). Conde and Musatto (2015) studied the effectiveness of hydrothermal

70 pretreatment strategy in the isolation of polyphenols from SCW. Similarly, Scully et al. (2016),

71 applied hydrothermal pretreatment for the industrially important sugars. However, the authors

72 were unable to come across any study that involved mimicking Fenton reaction using plasma for

73 lignocellulosic waste such as spent coffee waste and its potential application in bioethanol

74 production.

75 Plasma is the fourth state of matter. It contains atoms, ions and molecules in a metastable state

76 with a net electric charge of zero (Devi et al., 2017). Atmospheric plasma discharges may be

77 obtained artificially by many means of electromagnetic wave disturbances resulting from the

78 application of current or ionization radiation in way such that a measurable charge is created in

79 the gas without the generation of any heat. This gives rise to positively and negatively charged

80 electrons, intermediate highly reactive species $\left(\mathrm{H}^{\bullet}, \mathrm{O}^{\circ}, \mathrm{OH}^{\bullet}\right.$ etc. $)$ atoms, molecules and UV

81 photons with neutral charge (Sarangapani et al., 2015, Sarangapani et al., 2016). Ozone, one of

82 the reactive species generated because of atmospheric air plasma specifically degrades lignin

83 when lignocellulosic materials are subjected to plasma treatment. This leaves the solid fraction

84 rich in polysaccharides which can be utilised. Studies involving plasma as a pretreatment

85 measure have reported high dry matter concentration, relatively low pretreatment time, low

86 temperature of operation and absence of any inhibitory compounds as the major advantages. The

87 phenolic compounds that arise from the lignin degradation can be removed by simply washing

88 the solid material with water (Souza-Corrêa et al., 2014). 
89 Fenton chemistry is an oxidation reaction which gives rise to highly reactive free radicals. In the

90 presence of $\mathrm{Fe}^{3+}$ ion and $\mathrm{H}_{2} \mathrm{O}_{2}$ the ferric ion is oxidised to an $\mathrm{Fe}^{2+}$ ion resulting in the formation

91 of $\mathrm{H}_{2} \mathrm{O}$ and $\mathrm{O}_{2}$ along with two reactive species viz. $\mathrm{HO}^{\bullet}$ and $\mathrm{HOO}^{\bullet}$ (Fenton, 1894; Pignatello et

92 al., 2006). The Fenton reaction does not require high temperatures, pressure or any other

93 chemical in the form of a catalyst for initiation. However, it does require an acidic environment

94 (Jung et al., 2009). The generation of reactive species in the presence of $\mathrm{Fe}^{3+}$ can lead to the

95 occurrence of Fenton chemistry which can be used for the depolymerisation of lignin in plant

96 biomass. Several studies have reported where the Fenton reaction has been exploited as a

97 pretreatment measure (Jung et al., 2015; Kato et al., 2014).

98 Pretreatments can involve several parameters to achieve for effective delignification of

99 lignocellulose. In most common pretreatments such as dilute acid hydrolysis or organosolv

100 pretreatments, these parameters include acid concentration, temperature, pressure, ethanol

101 concentration etc. (Ravindran et al., 2017a). The abundance of parameters makes it difficult to

102 determine the optimal levels of each factor to attain the target objective. Taguchi design of

103 experiments describes an effective method to evaluate the effects of different parameters

104 statistically in a process that has multiple factors. Furthermore, it minimises the errors caused

105 due to variations in the experimental process. Taguchi design of experiments works by testing

106 the effects of varying parameters simultaneously. This allows the accurate estimation of

107 individual factors thus selecting the best combination for factors that will result in a robust

108 process (Azad et al., 2016).

109 In the present study, we investigate a new pretreatment strategy for lignocellulose by combining

110 a nonthermal plasma discharge and $\mathrm{Fe}^{3+}$ ions to create an environment for the Fenton reaction 
111 along with ozone to delignify lignocellulose, and spent coffee waste was chosen as a model. The

112 pretreatment process was optimised by the Taguchi Design of Experiments that involved five

113 parameters viz. biomass loading, acid concentration, ferric chloride concentration, voltage and

114 time. Furthermore, the pretreated SCW was enzymatically hydrolysed using the optimised

115 parameters and the hydrolysate obtained was employed for bioethanol production.

\section{Materials and methods}

\section{$117 \quad 2.1 \quad$ Feedstock and other chemicals}

118 Spent Coffee Waste (SCW) was collected from a local coffee outlet located in Dublin city. The

119 waste material was dried in a hot air oven at $80^{\circ} \mathrm{C}$ for $48 \mathrm{~h}$ (Kwon et al., 2013). The dried SCW

120 was then stored at room temperature in a cool and dry place for further experiments. All the

121 chemicals such as $\mathrm{FeCl}_{3}$, sulphuric acid and saccharifying enzymes such cellulase from

122 Trichoderma reesei and hemicellulase from Aspergillus niger were purchased from Sigma

123 Aldrich, Ireland. Cellulase was purchased in liquid form. Following protocols devised by

124 National Renewable Energy Laboratory (Adney \& Baker, 1996), the cellulase activity was

125 assayed. The hemicellulase, on the other hand, was obtained as powder form and dissolved in

126 sodium acetate buffer $(\mathrm{pH} 4.8,50 \mathrm{mM})$ to make up a concentration of $10 \mathrm{~g} / \mathrm{l}$. The subsequent

127 activity of the enzyme was assayed followed protocols described by Rickard and Laughlin

128 (1980). Cellulase enzyme registered an enzyme activity of 77 FPU/ml while hemicellulase

129 showed $72 \mathrm{U} / \mathrm{ml}$ enzyme activity. 


\subsection{Component analysis}

131 The compositional variations in SCW before and after pretreatment was analysed by using

132 protocols devised by the National Renewable Energy Laboratory, USA. As a control measure the

133 composition of native SCW was also determined. Biomass was hydrolysed by mixing it with

$13472 \% \mathrm{H}_{2} \mathrm{SO}_{4}$ for $60 \mathrm{~min}$ at $30^{\circ} \mathrm{C}$. The acid concentration was then diluted to $4 \%$ with deionised

135 water and autoclaved at $121^{\circ} \mathrm{C}$ for $1 \mathrm{~h}$. The solids were then separated from the liquids and dried

136 at $80^{\circ} \mathrm{C}$ for $48 \mathrm{~h}$ following which the acid insoluble lignin was determined by drying at $595^{\circ} \mathrm{C}$ for

137 24h. The liquid was assessed for the acid soluble lignin by measuring the absorbance at $205 \mathrm{~nm}$

138 and the sugar concentrations were determined by HPLC (Rezex ROA H${ }^{+}$, Waters e2695

139 Separation module, Refractive Index detector).

\section{$140 \quad 2.3 \quad$ Surface modification using atmospheric air pressure plasma}

141 Various parameters affecting the metal chloride assisted plasma pretreatment were optimised by

142 adopting a Taguchi design. Five parameters viz. biomass loading, ferric chloride concentration,

143 dilute acid concentration, time and voltage were taken in to consideration for experimental

144 design. Three levels were considered for each parameter. Based on these parameters and levels

145 an $\mathrm{L}_{27}$ orthogonal array of standard configuration of five 3 level factors was set up (Table 1) and

146 was generated by using Minitab $17^{\circledR}$. A prototype high voltage but low pawer $(\sim 150 \mathrm{~W})$ dielectric

147 barrier discharge plasma source was used for this study. The system consisted of a high voltage

148 transformer $(230 \mathrm{~V}, 50 \mathrm{~Hz})$, a ground electrode and voltage variac (output voltage can be

149 controlled from 0 to $120 \mathrm{kV}$ ). The optimisation trials were operated at 60,70 and $80 \mathrm{kV}$ as per

150 the experiment design. The input voltage and current was monitored by employing an 151 oscilloscope (InfiniVision 2000 X-Series Oscilloscope, Agilent Technologies Inc., USA) (Fig 1). 
152 The samples were held in the centre of a polypropylene container by means of a petri dish. On

153 completion of each trial, the containers were sealed in polypropylene bags (B2630; Cryovac

154 Sealed Air Ltd, Dunkan, SC, USA) and stored in a cool and dry place for the reaction to take

155 place (Lu et al., 2014). After pretreatment the solids were filtered out. Any residual $\mathrm{FeCl}_{3}$ was

156 removed by washing the solids five times with deionised water. They were then freeze dried and

157 stored for further experiments.

\section{$158 \quad 2.4 \quad$ Enzymatic hydrolysis}

159 The parameters for maximum reducing sugar production was derived from a study performed

160 previously in our laboratory (Ravindran et al., 2017b). Briefly, the pretreated SCW was

161 hydrolysed by employing a biomass loading of $1 \%$, cellulase and hemicellulase loading of $1.5 \mathrm{ml}$

162 (23.1 FPU/g of dry biomass) and $0.37 \mathrm{ml} \mathrm{(5.33} \mathrm{U/g}$ of dry biomass), respectively while

163 maintaining a $\mathrm{pH}$ of 6.7 . The ambient temperature for the reaction was maintained at $50^{\circ} \mathrm{C}$ while

164 the reaction volume was set to $50 \mathrm{ml}$. On completion of the experiments the suspensions were

165 transferred to $30 \mathrm{ml}$ polypropylene tubes, centrifuged at $7000 \mathrm{rpm}$ for 10 minutes. The

166 supernatant was collected and were checked for reducing sugar content using dinitrosalicylic

167 acid and the values obtained were input into the design software to decipher optimised hydrolysis

168 conditions.

$169 \quad 2.5 \quad$ Individual sugar, inhibitor and organic acid analysis

170 The presence and quantification of monosaccharides and organic acids was performed using a

171 Allaince HPLC (Waters, e2695 Separation module) with a Rezex ROA-Organic acid H+ (8\%)

172 column, (350 x $7.8 \mathrm{~mm}$; Phenomenex, UK) and $0.005 \mathrm{M} \mathrm{H}_{2} \mathrm{SO}_{4}$ as the mobile phase at $65^{\circ} \mathrm{C}$

173 maintaining a flow rate of $0.6 \mathrm{ml} / \mathrm{min}$ (Jaiswal et al., 2012). The same type of guard column was 
174 used with the regular column and was kept outside the compartment to avoid overheating beyond

175 the manufacturers recommended limit $\left(60^{\circ} \mathrm{C}\right)$. An isocratic mobile phase of $0.01 \mathrm{M}$ sulphuric acid

176 was used to detect and estimate the number of inhibitors such as furfural and hydroxymethyl

177 furfural in the hydrolysate. The HPLC system was equipped with an autosampler, degasser and a

$178 \mathrm{UV}$ detector $(210 \mathrm{~nm})$ and a refractive index (RI) detector.

\section{$179 \quad 2.6 \quad$ Bioethanol production}

180 The sugar rich hydrolysate, free from undissolved solids, obtained after saccharification was

181 subjected to fermentation to produce bioethanol. Saccharomyces cerevisiae obtained from the

182 DIT microbiology repository was employed as the fermentative microorganism. For inoculation,

183 the microbe was grown in a medium containing glucose $(1 \mathrm{~g} / 100 \mathrm{ml})$, and yeast extract

$184(0.1 \mathrm{~g} / 100 \mathrm{ml})$ supplemented by $\left(\mathrm{NH}_{4}\right)_{2} \mathrm{SO}_{4}(0.5 \mathrm{~g} / 100 \mathrm{ml}), \mathrm{MgSO}_{4} \cdot 7 \mathrm{H}_{2} \mathrm{O}(0.05 \mathrm{~g} / 100 \mathrm{ml})$ and $185 \mathrm{KH}_{2} \mathrm{PO}_{4}(0.1 \mathrm{~g} / 100 \mathrm{ml})$ and was incubated at $30^{\circ} \mathrm{C}$ and $120 \mathrm{rpm}$ for $18 \mathrm{~h}$. For bioethanol 186 production, $0.5 \mathrm{ml}$ of actively growing culture of $S$. cerevisiae was added into the reaction 187 mixture. The reaction mixture consisted of the hydrolysate which was supplemented with yeast 188 extract $(0.1 \%)$ and peptone $(0.1 \%)$ was autoclaved at $121^{\circ} \mathrm{C}$ for 15 minutes. The $\mathrm{pH}$ was 189 maintained by the addition of $1 \%(\mathrm{v} / \mathrm{v})$ acetate buffer $(\mathrm{pH} 5.4,20 \mathrm{mM})$. Fermentation was carried 190 out in $100 \mathrm{ml}$ conical flasks with a total reaction volume of $50 \mathrm{ml}$ at $30^{\circ} \mathrm{C}$ for $72 \mathrm{~h}$. After

191 fermentation, the reaction mixture was centrifuged and filtered using $0.4 \mu$ filters and the ethanol 192 produced was quantified by using Gas Chromatography [Bruker Scion 456-GC coupled with 193 flame ionisation detector (FID)]. The injector temperature was set at $220^{\circ} \mathrm{C}$ while the column 194 oven was set at an initial temperature of $80^{\circ} \mathrm{C}$. which was ramped up to $160^{\circ} \mathrm{C}$ at a rate of $40^{\circ} \mathrm{C}$ 
195 per min and held for 7 minutes. A flame ionisation detector was used to analyse the ethanol

196 content and set at a temperature of $200^{\circ} \mathrm{C}$.

$197 \quad 2.7$ Characterisation of pretreated SCW

$198 \quad$ 2.7.1 X-ray diffraction

199 X-ray diffraction studies were employed to study any changes imparted in the crystallinity of the

200 lignocellulose substrate by the pretreatment strategy (Ravindran et al., 2017c) XRD of the

201 pretreated and native SCW was performed in a Siemens D-500 X-ray diffractometer. The voltage

202 and current for the radiation were set at $40 \mathrm{kV}$ and $30 \mathrm{~mA}$ using $\mathrm{Cu} \mathrm{K \alpha}$ as the radiation source

$203(\lambda=0.154 \mathrm{~nm})$. The diffraction angles were spanned at $2 \theta^{\circ}=5^{\circ}-50^{\circ}$.

\section{$204 \quad$ 2.7.2 $\quad$ FTIR analysis}

205 FTIR spectroscopy was performed on raw and pretreated SCW to identify possible structural 206 changes as a reflection of the variations in the functional groups in the SCW before and after 207 pretreatment. A Perkin Elmer Spectrum GX FT-IR (UATR) Microscope (USA) was employed in 208 this study as per the method described in Ravindran et al. (2017c). In brief, the FTIR spectra for 209 SCW samples were recorded from 4000 to $400 \mathrm{~cm}^{-1}$ with 16 scans at a resolution of $0.3 \mathrm{~cm}^{-1}$ in 210 transmission mode.

\section{$211 \quad$ 2.7.3 Thermal Behaviour study using DSC}

212 Differences in the thermal behaviour of SCW after pretreatment was studied using differential

213 scanning calorimetry (DSC), using $55 \mathrm{mg}$ of the pretreated SCW in an aluminium pan with an 214 empty pan used as a reference. The thermograms were obtained by increasing the temperatures 215 from $20^{\circ} \mathrm{C}$ to $500^{\circ} \mathrm{C}$ at a rate of $10^{\circ} \mathrm{C}$ per min at a constant nitrogen atmosphere. All 
216 measurements were carried out between $25^{\circ} \mathrm{C}$ and $500^{\circ} \mathrm{C}$ with a linear increase of $10^{\circ} \mathrm{C}$ in a

217 Shimadzu DSC-60 installed with TA-60WS software.

$218 \quad 2.8 \quad$ Estimation of total phenolic content

219 The total phenolic content in the pretreatment liquor was determined by following protocol

220 described by (Jaiswal et al., 2013). Briefly, $100 \mu \mathrm{l}$ of sample was mixed with $2 \mathrm{ml}$ of $2 \mathrm{mM}$

$221 \mathrm{Na}_{2} \mathrm{CO}_{3}$ solution and incubated for $2 \mathrm{~min}$ at room temperature. $100 \mu \mathrm{l}$ of $1 \mathrm{~N}$ Folin-Ciocalteau's

222 phenol reagent was added followed by incubation for $30 \mathrm{~min}$ in darkness at room temperature.

223 After the reaction was complete, the absorbance was measured at $720 \mathrm{~nm}$. The results were

224 expressed as microgram per $\mathrm{ml}$ of the sample through calibration curve of gallic acid.

\section{$225 \quad 2.9$ Determination of hydrogen peroxide concentration}

226 Hydrogen peroxide formed because of plasma treatment was quantified by oxidising potassium

227 iodide measuring the amount of iodine formed using spectrophotometry at $390 \mathrm{~nm}$. In brief, 100

$228 \mu \mathrm{l}$ of $1 \mathrm{M}$ KI solution and $50 \mu \mathrm{l}$ of phosphate buffer were mixed with $50 \mu$ l of plasma treatment

229 liquor. The mixture was incubated for 30 minutes after which the absorbance was measured at $230390 \mathrm{~nm}$ (Boehm et al., 2016).

\section{$231 \quad 2.10$ Optical emission spectroscopy}

232 Optical emission spectroscopy was performed to determine the active chemical species formed

233 during the non-thermal plasma discharge. This was carried out using a Stellarnet EPP 2000C-25

234 spectrometer at a resolution of $1.5 \mathrm{~nm}$. The light from the plasma was coupled via an optical

235 fibre. The diffraction grating in the spectrometer had a radius of curvature of $40 \mathrm{~mm}$ with 590

236 grooves per $\mathrm{mm}$ and an entrance slit width of $25 \mu \mathrm{m}$. The fibre (numerical aperture $=0.22$ ) was 
237 optimised for performance in the ultraviolet and visible region of electromagnetic spectrum. The

238 spectrometer operated within the wavelength range of $190 \mathrm{~nm}$ to $850 \mathrm{~nm}$. The integration time

239 was set at $5000 \mathrm{~ms}$ and 5 samples were averaged for the collection of spectra. The emission

240 spectra were qualitatively analysed to assign chemical species to the peaks. The noise in the

241 spectra was cancelled, averaged and analysed using National Institute of Standards and

242 Technology (2012) atomic spectra database and literature published elsewhere (Meiners., 2010).

\section{$243 \quad 2.10 .1$ Statistical Analysis}

244 Quantitative experimental tests were carried out in triplicate and the results are reported as the

245 mean \pm the standard deviation. The Taguchi statistical analysis was conducted by employing

246 MINITAB 17 software. To evaluate the sensitivity of each parameter, determine the optimum

247 combination of operating parameters a variance analysis (ANOVA) was performed at confident 248 level of $95 \%$.

\section{Results and discussion}

\section{$250 \quad 3.1 \quad$ Effect of pretreatment on the composition of spent coffee waste}

251 The Fenton reaction involves the generation of hydroxyl radicals or similarly powerful oxidising

252 agents in the presence of a metal ion such as iron or hydrogen peroxide. One of the several

253 chemical reactions involved in Fenton chemistry includes the depolymerisation of lignin by

254 dealkylation which then facilitates the enzymatic digestion of cellulose and hemicellulose

255 components (Arantes et al., 2012). This novel pretreatment strategy attempts to delignify SCW

256 by means of providing a suitable environment for the Fenton reaction to take place by providing

257 ferric ions and hydrogen peroxide while maintaining a low $\mathrm{pH}$. Composition analysis of native 258 and plasma pretreated SCW was performed to determine the changes in individual components 
brought about by the pretreatment strategy. Native SCW was rich in glucomannan and 260 galactomannan content which was evident from the galactose $(13.7 \pm 0.3 \mathrm{~g} / 100 \mathrm{~g}$ of $\mathrm{SCW})$ and

261 mannose $(21.2 \pm 0.5 \mathrm{~g} / 100 \mathrm{~g}$ of SCW $)$ content with respect to glucose $(8.6 \pm 0.1 \mathrm{~g} / 100 \mathrm{~g}$ of SCW $)$.

262 Trace amounts of arabinose was also found in SCW $(1.7 \pm 0.2 \mathrm{~g} / 100 \mathrm{~g}$ of SCW $)$. Similar findings

263 were reported by (Ballesteros et al., 2015; Ballesteros et al., 2014). On the other hand, the plasma

264 pretreated SCW consisted of $18.76 \pm 0.2 \mathrm{~g}$ of galactose, $24.51 \pm 1.3 \mathrm{~g}$ of mannose, $10.74 \pm 0.9 \mathrm{~g}$ of 265 glucose and $2.24 \pm 1.2 \mathrm{~g}$ of arabinose per $100 \mathrm{~g}$ of SCW. From the results, it is evident that there 266 was an increase in the total polysaccharide content in SCW after the pretreatment. As with lignin 267 content, the acid insoluble lignin reduced from $31.12 \pm 0.2 \mathrm{~g}$ in native SCW to $18.6 \pm 0.45 \mathrm{~g}$ in 268 pretreated SCW (per 100g SCW).

\subsection{Effect of different process parameters on metal chloride assisted plasma} pretreatment

271 Table 1 represents the Taguchi experimental design and associated reducing sugar results

272 obtained in the study. Results showed a maximum reducing sugar yield was obtained from trial

273 no. $26(0.493 \mathrm{~g} / \mathrm{g}$ of SCW) (refer Table 1). The pretreatment parameters for this trial was found

274 to be $12.5 \%$ biomass loading, $3 \% \mathrm{FeCl}_{3}$ concentration, $1 \% \mathrm{H}_{2} \mathrm{SO}_{4}$ concentration, exposure time 275 of $2 \mathrm{~min}$ and a voltage of $70 \mathrm{kV}$. Fig 2 comprises of contour plots that depict the interactions of

276 the process parameters considered in this study that contribute to the release of reducing sugar 277 after enzymatic hydrolysis of the pretreated SCW. A general trend observed was that a higher

278 biomass content resulted in higher reducing sugar concentration after enzymatic hydrolysis.

279 From Fig 2a, it is evident that a high biomass content (\% w/v) exposed to plasma for lower time 280 periods (min) was favourable in enhancing the reducing sugar yield. At a biomass concentration 
281 of $12.5 \%(\mathrm{w} / \mathrm{v})$ and a plasma exposure time of around $2 \mathrm{~min}$ the reducing sugar release was

282 found to be in the range of $0.40 \mathrm{~g} / \mathrm{g}$ of pretreated SCW. Increasing the exposure time

283 detrimentally effected the reducing sugar yield. This was possibly because of the extensive

284 damage incurred by the polysaccharide fraction along with lignin which left less cellulose and

285 hemicellulose for enzymatic degradation.

286 Fig $2 \mathrm{~b}$ represents the effects of voltage and biomass on the eventual release of the reducing sugar

287 from SCW in the form on a contour plot. From the plot, it is evident that low voltages and low

288 biomass loading rates (8-10\%) was largely ineffective in breaking down the complex

289 lignocellulose structure as the reducing sugar yield was low. As the voltage increases $(70-80 \mathrm{kV})$

290 the effectiveness of the pretreatment increases. At higher voltages, higher concentrations of

291 reactive species are generated which in turn accelerates the delignifying degradation process

292 (Moiseev et al., 2014). Fig 2c shows the relationship between $\mathrm{H}_{2} \mathrm{SO}_{4}$ concentration and biomass.

293 A lower concentration of acid (1\% acid conc.) was found to favour higher reducing sugar

294 formation. This could be because the higher concentrations of acid tend to produce inhibitory

295 compounds which negatively affect enzymatic hydrolysis. Fig 2d shows the interaction between

$296 \mathrm{FeCl}_{3}$ concentration and biomass loading. A higher concentration of $\mathrm{FeCl}_{3}$ resulted in higher

297 reducing sugar yields. This may be because of the accelerated generation of reactive radicals are

298 a result of the Fenton chemistry due to higher concentrations of $\mathrm{Fe}^{3+}$ ions.

\section{$299 \quad 3.3$ Statistical analysis and regression model equation}

300 The ANOVA outputs performed on the $\mathrm{L}_{25}$ Taguchi Orthogonal Array is provided in table 2.

301 ANOVA studies gave insights on the role of each parameter based on Fischer's test (F-value),

302 probability and sum of squares to check the significance of each parameter in the model. A large 
303 F-value is suggestive of the importance of a parameter applied in the process. Accordingly, three

304 parameters viz. biomass loading, $\mathrm{FeCl}_{3}$ conc. and $\mathrm{H}_{2} \mathrm{SO}_{4}$ conc. were found to have higher $\mathrm{F}$ -

305 values compared to voltage and time. Acid concentration had the most prominent effect on the

306 reducing sugar yield with an F-value of 244.84 followed by $\mathrm{FeCl}_{3}$ conc. (F-value=151.2) and

307 lastly biomass loading (F-value=113.04) Furthermore, only three parameters (biomass loading,

$308 \mathrm{FeCl}_{3}$ conc. and $\mathrm{H}_{2} \mathrm{SO}_{4}$ conc.) were found to be significant $(p<0.05)$ with respect to influencing

309 reducing sugar yield. Voltage did not have a significant impact $(\mathrm{p}>0.05)$ on the effectiveness of

310 the pretreatment. A similar observation was reported by Misra et al. (2015), where atmospheric

311 air pressure plasma was used to study the variations in anthocyanin content in strawberries. The

312 variability in observations of this study can be attributed to the change in plasma chemistry due

313 to variations in the nature of the lignocellulosic substrate which have not been included in this

314 study.

315 A regression model equation was generated as a part of the ANOVA study which comprised all

316 the factors considered in this study. This equation can predict the reducing sugar yield according

317 to any set of parametric settings within the range of the process parameters. The regression

318 equation is as follows:

319 Reducing sugar $(\mathrm{g} / \mathrm{g})=0.1864+0.01827 *$ biomass loading $+0.05798 * \mathrm{FeCl}_{3}$ conc. -

$$
0.1473 * \mathrm{H}_{2} \mathrm{SO}_{4} \text { conc. }-0.00609 * \text { time }+0.001188 * \text { voltage }
$$

321 From a high $\mathrm{R}^{2}$ value of $96.42 \%$ and the adjusted $\mathrm{R}^{2}$ of $95.56 \%$ illustrated that the model 322 adequately fit the data. 


\subsection{Incidence of inhibitors in pretreatment liquor}

324 The pretreatment liquor was subjected to HPLC analysis to determine any incidence of inhibitory 325 or monosaccharide components. As was expected trace amounts of individual sugars such as

326 glucose, galactose and mannose and, a small fraction of cellobiose was found in the liquor. An 327 interesting finding was the presence of hydroxymethyl furfural (HMF) in the treatment liquors 328 which were high in sulphuric acid concentration. The concentration ranges of HMF in 329 pretreatment liquors ranged from $0.5 \mathrm{~g}$ to $1.2 \mathrm{~g} / 100 \mathrm{~g}$ of SCW. This may have been detrimental in

330 the enzymatic hydrolysis of the pretreated SCW. It has been well documented that glucose in 331 acidified solutions can give rise to hydroxymethyl furfural (Van Dam et al., 1986). The 332 inhibitory compounds may have been formed by the degradation of glucose by acid. The 333 increasing intensity of plasma coupled with the higher exposure times may have accelerated the 334 process of HMF formation.

\subsection{FTIR, XRD and DSC profiles of untreated and pre-treated spent coffee waste}

336 Fourier Transform Infrared Spectroscopy is used to identify or analyse the changes induced by a

337 pretreatment process on lignocellulosic residues. Each component in lignocellulose (cellulose, 338 hemicellulose and lignin) will have bonds and functional groups that are specific to each of them.

339 Any changes in structure such as the breakage of bonds or removal of fractions can result in 340 changes that can identified in the FTIR spectra. The peaks at $897 \mathrm{~cm}^{-1}$ represents glycosidic 341 linkage between cellulose and hemicellose components. The peak intensity was considerably 342 lower in the spectrum of the pretreated SCW. The absorbance of band at $1035 \mathrm{~cm}^{-1}$, which 343 indicates $\mathrm{C}-\mathrm{O}, \mathrm{C}=\mathrm{C}$ and $\mathrm{C}-\mathrm{C}-\mathrm{O}$ stretching between polysaccharides and lignin decreased after 344 pretreatment (Tamaki and Mazza, 2011). Furthermore, the decrease in band $1200 \mathrm{~cm}^{-1}$ indicated 
345 the breakage of hydrogen bonds between cellulose and hemicellulose. The peak at $1290 \mathrm{~cm}^{-1}$ is 346 associated with the crystallinity of SCW (Binod et al., 2012). This peak was found to be

347 diminished in the pretreated SCW spectrum. The band at $1400 \mathrm{~cm}^{-1}$ is representative of the 348 lignin present in the sample. This band was seen to be considerably reduced which indicates that 349 the plasma pretreatment was effective in lignin removal. Band $1750 \mathrm{~cm}^{-1}$ is an indication of the 350 ketone/aldehyde bonds in hemicellulose (Bodirlau and Teaca, 2009). A peak for this region was 351 found in the pretreated sample spectrum, albeit in lower intensity, probably due to the stretching 352 of these bonds. The band $2920 \mathrm{~cm}^{-1}$ represents methyl and methylene groups in lignocellulose 353 (Haripriya et al., 2014). These bands were not as prominent in the pretreated sample spectra, 354 which is an indication of possible demethylation of SCW by reactive radicals generated during 355 the plasma treatment. The absence of peaks in the band range $3000-3500 \mathrm{~cm}^{-1}$ is indicative of 356 stretching of -OH groups for the pretreated SCW (Jahan et al., 2011).

357 Lignocellulose is generally crystalline as well as amorphous in nature due to its chemical 358 composition. Cellulose is the component in plant biomass that provides its crystallinity. 359 Crystalline cellulose is more resistant to degradation due to chemical, enzymatic or microbial 360 attack compared to its amorphous counter-part. Conversely, hemicellulose is amorphous in 361 nature and is susceptible to degradation by chemical agents or microorganisms. The efficient 362 utilisation of cellulose involves a shift from its crystalline nature to amorphous form (Ravindran 363 \& Jaiswal, 2016b). X-ray diffraction studies help to understand the crystallinity of the of 364 lignocellulose. Peaks at $2 \theta=22^{\circ}$ are indicative of the crystallinity of the material. Meanwhile, 365 peaks at $2 \theta=18^{\circ}$ represents the amorphous regions in a lignocellulosic substrate. Native SCW 366 was found to be a mixture of equally crystalline and amorphous with broad peaks ranging from $3672 \theta=15^{\circ}$ to $2 \theta=25^{\circ}$. However, in the plasma pretreated SCW there was an absence of such peaks 
368 in the crystalline region. Coupled with the development of peaks in the amorphous region it is

369 clear that the plasma treatment leads to decrease in crystallinity of lignocellulose. Although not

370 many studies are available on the changes brought about by air plasma on lignocellulosic fibres,

371 (Baltazar-Y-Jimenez \& Bismarck, 2007) reported that the crystallinity of cellulose fibres is

372 affected by the plasma treatment.

373 Thermal behaviour studies of lignocellulose before and after pretreatment were conducted to

374 analyse the changes in the biomass in terms of its properties as a polymer. This was performed

375 using differential scanning calorimetry (DSC). DSC provides insights into the physical and

376 chemical characteristics of lignocellulose. Several properties such as crystallisation, heat

377 capacity, melting, crystalline orientation and glass transition can be recorded using DSC. The

378 changes induced by the pretreatment in the thermal behaviour of lignocellulose has been widely

379 studied by several researchers (Ballesteros et al., 2014; Nguyen et al., 1981). Therefore, DSC

380 was performed to study the changes induced in the physical properties of SCW after plasma

381 pretreatment. The DSC thermograms are provided as Fig. 3. The thermogram for native SCW

382 was marked by an exothermic event between $20^{\circ} \mathrm{C}$ and $102.9^{\circ} \mathrm{C}$ with an associated enthalpy of

$383114.99 \mathrm{~J} / \mathrm{g}$. This may have occurred because of vaporisation of water and the crystalline nature of

384 the sample. The exothermic event was followed by a phase transformation inducing a change in

385 the heat capacity. The glass transition temperature was recorded at $259.2^{\circ} \mathrm{C}$. The effect of plasma

386 on the physical properties of SCW was evident as there were marked differences between the

387 thermograms of the pretreated and native SCW. The DSC thermogram for plasma treated SCW

388 showed distinct peaks that suggested an event for glass transition, crystallisation, melting and

389 ending transient. The glass transition temperature was recorded at $283^{\circ} \mathrm{C}$. 
391 Exposing aqueous solutions to plasma discharge results in the generation of large amounts of 392 hydrogen peroxide. This results in the initiation of Fenton reaction that further degrades

393 individual components in lignocellulose such as lignin. The hydrogen peroxide in the 394 pretreatment liquor formed was quantified. It was found that the liquid obtained after 395 pretreatment contained $647.28 \mu \mathrm{M}$ of hydrogen peroxide after $24 \mathrm{~h}$ of plasma treatment. A 396 majority of the $\mathrm{H}_{2} \mathrm{O}_{2}$ formed is due to its solubilisation from gaseous phase into liquid phase.

397 Therefore, by retaining the reactive species in the gas phase in contact with the liquid phase for 398 longer periods time higher amounts of $\mathrm{H}_{2} \mathrm{O}_{2}$ could diffuse into the liquid. Furthermore, earlier 399 studies confirmed that concentrations of $\mathrm{H}_{2} \mathrm{O}_{2}$ in solutions subjected to plasma treatment were 400 stable over several weeks when stored in closed containers at $4^{\circ} \mathrm{C}$ (Boehm et al., 2016).

401 Spent coffee waste is high in phenolic compounds. The effect of plasma on the phenolic content 402 of pretreatment liquor was analysed by Folin-Ciocalteau's phenol reagent. The control contained $403908.35 \mu \mathrm{g} \mathrm{GAE} / \mathrm{g}$ of SCW while the pretreated liquor contained $672.86 \mu \mathrm{g} \mathrm{GAE} / \mathrm{g}$ of SCW. 404 Exposing SCW to dielectric barrier discharge plasma resulted in the total phenolic content by $40526 \%$ for an experimental setting of $70 \mathrm{kV}$ and $2 \mathrm{~min}$. The reduction in total phenolic content can 406 be attributed to the formation of reactive species and the availability of oxygen in the atmosphere 407 which actively degraded phenolic compounds in SCW (Ramazzina et al., 2016). Earlier studied 408 conducted by Grzegorzewski et al. (2011) reported a reduced phenolic content in lamb lettuce 409 leaves when treated with atmospheric air pressure plasma. 
411 The chemical reactive species in the gas phase formed during the dielectric barrier discharge was 412 analysed by optical emission spectroscopy (OES). The spectrum of the radiation emitted by the

413 plasma was grated and the intensity was measured as function of the wavelength (Fig 4). The 414 non-thermal plasma was operated at voltage of $70 \mathrm{kV}$ the emission spectra was obtained for a 415 wavelength range of $180-900 \mathrm{~nm}$. The emission spectrum revealed that the emission was near the 416 UV region (300-400nm). Emissions from $\mathrm{N}_{2}$ and $\mathrm{N}_{2}{ }^{+}$species exhibited distinct peaks. The small 417 peaks observed at the region corresponding to $250-300 \mathrm{~nm}$ were a resultant of the presence of $418 \mathrm{OH}$. Meanwhile the very low intensity peaks observed at $750 \mathrm{~nm}$ and $780 \mathrm{~nm}$ corresponded to 419 singlet oxygen. The formation of singlet $\mathrm{O}$ may be attributed to the particle collisions as well as 420 the quenching of $\mathrm{O}\left({ }^{3} \mathrm{P}\right)$ and $\mathrm{O}\left({ }^{5} \mathrm{P}\right)$ energy. Similar observations were reported by Pearse et al. 421 (1976) and Laux et al. (2003) in different studies involving identification of molecular spectra 422 and atmospheric air pressure plasma. From these inferences, it was quite clear that a certain 423 amount of lignin degradation was achieved by reactive species formed during plasma treatment.

\section{$424 \quad 3.8 \quad$ Bioethanol production using plasma treated SCW}

425 SCW was found to be a potential candidate for bioethanol production. The hydrolysate obtained 426 after enzymatic digestion of the plasma pretreated SCW was used for bioethanol production 427 using S. cerevisiae. A maximum ethanol content of $18.642 \mathrm{~g} / \mathrm{l}$ was obtained after fermentation 428 for $72 \mathrm{~h}$. The bioethanol production using the control sample yielded $9.231 \mathrm{~g} / \mathrm{l}$ of ethanol. A 2 429 fold increase in bioethanol yield using the optimized process parameters was found with a 430 fermentation efficiency of $74 \%$. This result is inline with previous studies carried out by Kwon et 431 al. (2013), which reported a high ethanol fermentation efficiency of $80 \%$ using lipid extracted 
432 SCW. Similar findings were reported by Sindhu et al. (2011) where they optimised dilute acid

433 pretreatment for the processing of sugar cane trash and eventual bioethanol production to obtain

434 a titre of $11.365 \mathrm{~g} / \mathrm{l}$.

\section{Conclusion}

436 Ferric chloride assisted plasma processing of SCW was found to be an effective pretreatment

437 strategy with high lignin removal capacity. This resulted in an enhanced enzymatic digestion and

438 high fermentation efficiency for ethanol production. A Taguchi design of experiments was

439 successful in optimising the parameters for the plasma treatment. A maximum effectiveness of

440 the pretreatment was achieved after a short treatment duration of 2 min at a voltage of $70 \mathrm{kV}$ and

441 in the presence of $1 \% \mathrm{H}_{2} \mathrm{SO}_{4}$. To our knowledge there are limited experiments employing

442 atmospheric air plasma as a lignocellulose pretreatment measure let alone trying to mimic Fenton

443 chemistry using plasma for delignification of plant biomass and subsequent bioethanol 444 production.

445

446 Appendix A. Supplementary data Supplementary data associated with this article can be found, 447 in the online version, at $\operatorname{xxxxx}$

\section{References}

450 1. Azad, F.N., Ghaedi, M., Dashtian, K., Hajati, S. and Pezeshkpour, V. 2016.

Ultrasonically assisted hydrothermal synthesis of activated carbon-HKUST-1-MOF hybrid for efficient simultaneous ultrasound-assisted removal of ternary organic dyes and antibacterial investigation: Taguchi optimization. Ultrason. Sonochem. 31, 383-393. 
2. Bodirlau, R. and Teaca, C.A., 2009. Fourier transform infrared spectroscopy and thermal analysis of lignocellulose fillers treated with organic anhydrides. Rom. J. Phys, 54, 93104.

3. Ballesteros, L.F., Cerqueira, M.A., Teixeira, J.A., Mussatto, S.I. 2015. Characterization of polysaccharides extracted from spent coffee grounds by alkali pretreatment. Carbohydr. Polym. 127, 347-354.

4. Ballesteros, L.F., Teixeira, J.A., Mussatto, S.I. 2014. Chemical, functional, and structural properties of spent coffee grounds and coffee silverskin. Food Bioprocess Technol. 7, 3493-3503.

5. Baltazar-Y-Jimenez, A., Bismarck, A. 2007. Surface modification of lignocellulosic fibres in atmospheric air pressure plasma. Green Chem. 9, 1057-1066.

6. Binod, P., K. Satyanagalakshmi, R. Sindhu, K. U. Janu, R. K. Sukumaran and A. Pandey. 2012. Short duration microwave assisted pretreatment enhances the enzymatic saccharification and fermentable sugar yield from sugarcane bagasse. Renew. Energy, 37 , 109-116.

7. Boehm, D., Heslin, C., Cullen, P.J., Bourke, P. 2016. Cytotoxic and mutagenic potential of solutions exposed to cold atmospheric plasma. Sci. Rep. 6, 21464

8. Campbell, T.J., Teymouri, F., Bals, B., Glassbrook, J., Nielson, C.D., Videto, J. 2013. A packed bed Ammonia Fiber Expansion reactor system for pretreatment of agricultural residues at regional depots. Biofuels, 4, 23-34.

9. Chen, L., Chen, R. and Fu, S., 2015. $\mathrm{FeCl}_{3}$ pretreatment of three lignocellulosic biomass for ethanol production. ACS Sustain. Chem. Eng., 3, 1794-1800 
10. Devi, Y., Thirumdas, R., Sarangapani, C., Deshmukh, R.R. and Annapure, U.S., 2017. Influence of cold plasma on fungal growth and aflatoxins production on groundnuts. Food Control. 77, 187-191.

11. Fenton, H. 1894. LXXIII.-Oxidation of tartaric acid in presence of iron. J. Chem. Soc. Trans. 65, 899-910.

12. Grzegorzewski, F., Ehlbeck, J., Schlüter, O., Kroh, L.W. and Rohn, S., 2011. Treating lamb's lettuce with a cold plasma-Influence of atmospheric pressure Ar plasma immanent species on the phenolic profile of Valerianella locusta. LWT-Food Sci. Technol., 44, 2285-2289.

13. Haripriya, R., Selvaraj, C., Naveenraj, D., Kirubakaran, S.A., Muthukumar, V., Thirumalaivasan, P., 2014. Pretreatment of cellulosic waste materials. Eur. J. Biotech. Biosci. 2, 4-13.

14. International Coffee Organization (ICO), 2016. The Current State of the Global Coffee Trade.

15. Jaiswal, A.K., Abu-Ghannam, N., 2013. Kinetic studies for the preparation of probiotic cabbage juice: Impact on phytochemicals and bioactivity. Ind. Crop. Product. 50, 212218.

16. Jaiswal, A.K., Gupta, S., Abu-Ghannam, N. 2012. Optimisation of lactic acid fermentation of York cabbage for the development of potential probiotic products. Int. J. Food Sci. Technol. 47, 1605-1612.

17. Jahan, M.S., Saeed, A., He, Z. and Ni, Y. 2011. Jute as raw material for the preparation of microcrystalline cellulose. Cellulose. 18, 451-459. 
18. Jung, Y.H., Kim, H.K., Park, H.M., Park, Y.-C., Park, K., Seo, J.-H., Kim, K.H. 2015. Mimicking the Fenton reaction-induced wood decay by fungi for pretreatment of lignocellulose. Bioresour. Technol. 179, 467-472.

19. Jung, Y.S., Lim, W.T., Park, J.Y., Kim, Y.H. 2009. Effect of pH on Fenton and Fenton-like oxidation. Environ. Technol. 30, 183-190.

20. Kato, D.M., Elía, N., Flythe, M., Lynn, B.C. 2014. Pretreatment of lignocellulosic biomass using Fenton chemistry. Bioresour. Technol. 162, 273-278.

21. Kramida, A., Ralchenko, Y. and Reader, J., NIST Atomic Spectra Database. 2012. Online: http://physics. nist. gov/asd.

22. Kwon, E.E., Yi, H., Jeon, Y.J. 2013. Sequential co-production of biodiesel and bioethanol with spent coffee grounds. Bioresour. Technol. 136, 475-480. high-voltage atmospheric cold plasma: influence of process parameters and effects on cell leakage and DNA. J. Appl. Microbiol. 116, 784-794.

26. Nguyen, T., Zavarin, E., barrall, E.M. 1981. Thermal Analysis of Lignocellulosic Materials. J. Macromol. Sci. Part C, 20, 1-65. of nonthermal plasma on chemical quality of strawberries. Postharvest Biol. Technol. 110, 197-202.

27. Pearse, R.W.B. and Gaydon, A.G., 1976. Identification of molecular spectra. Chapman and Hall. 
28. Pignatello, J.J., Oliveros, E., MacKay, A. 2006. Advanced oxidation processes for organic contaminant destruction based on the Fenton reaction and related chemistry. Crit. Rev. Env. Sci. Tech. 36, 1-84.

29. Ramazzina, I., Tappi, S., Rocculi, P., Sacchetti, G., Berardinelli, A., Marseglia, A. and Rizzi, F., 2016. Effect of Cold Plasma Treatment on the Functional Properties of FreshCut Apples. J. Agric. Food Chem., 64(42), pp.8010-8018.

30. Ravindran, R., Jaiswal, A.K. 2016a. A comprehensive review on pre-treatment strategy for lignocellulosic food industry waste: challenges and opportunities. Bioresour. Technol. 199, 92-102.

31. Ravindran, R., Jaiswal, A.K. 2016b. Exploitation of food industry waste for high-value products. Trend. Biotechnol. 34, 58-69.

32. Ravindran, R., Jaiswal, S., Abu-Ghannam, N. Jaiswal, A.K., 2017a. Two-Step Sequential Pretreatment for the Enhanced Enzymatic Hydrolysis of Coffee Spent Waste. Bioresour. Technol. 239, 276-284.

33. Ravindran, R., Jaiswal, S., Abu-Ghannam, N., Jaiswal, A.K. 2017b. Evaluation of ultrasound assisted potassium permanganate pre-treatment of spent coffee waste. Bioresour. Technol. 224, 680-687.

34. Ravindran, R., Jaiswal, S., Abu-Ghannam, N. Jaiswal, A.K., 2017. A comparative analysis of pretreatment strategies on the properties and hydrolysis of Brewers' spent grain. Bioresour. Technol. (DOI: 10.1016/j.biortech.2017.06.039).

35. Rickard, P., Laughlin, T. 1980. Detection and assay of xylanolytic enzymes in a Cellulomonas isolate. Biotechnol. Lett. 2, 363-368. 
36. Rocha, G.J.M., Gonçalves, A.R., Nakanishi, S.C., Nascimento, V.M., Silva, V.F.N. 2015. Pilot scale steam explosion and diluted sulfuric acid pretreatments: Comparative study aiming the sugarcane bagasse saccharification. Ind. Crop. Product. 74, 810-816.

37. Sarangapani, C., Devi, Y., Thirundas, R., Annapure, U.S., Deshmukh, R.R. 2015. Effect of low-pressure plasma on physico-chemical properties of parboiled rice. LWT - Food Sci. Technol. 63, 452-460.

38. Sarangapani, C., Misra, N.N., Milosavljevic, V., Bourke, P., O’Regan, F., Cullen, P.J. 2016. Pesticide degradation in water using atmospheric air cold plasma. J. Water Process Eng. 9, 225-232.

39. Sarangapani, C., Thirumdas, R., Devi, Y., Trimukhe, A., Deshmukh, R.R. and Annapure, U.S., 2016. Effect of low-pressure plasma on physico-chemical and functional properties of parboiled rice flour. Food Sci. Technol., 69, 482-489.

40. Schultz-Jensen, N., Kádár, Z., Thomsen, A.B., Bindslev, H. and Leipold, F., 2011. Plasma-assisted pretreatment of wheat straw for ethanol production. Appl. Biochem. Biotechnol., 165, 1010-1023.

42. Sindhu, R., Kuttiraja, M., Binod, P., Janu, K.U., Sukumaran, R.K., Pandey, A. 2011.

41. Scully, D. S., Jaiswal, A. K., \& Abu-Ghannam, N. 2016. An investigation into spent coffee waste as a renewable source of bioactive compounds and industrially important sugars. Bioengineering, 3, 33.

43. Souza-Corrêa, J.A., Oliveira, C., Nascimento, V.M., Wolf, L.D., Gómez, E.O., Rocha, G.J.M. and Amorim, J., 2014. Atmospheric pressure plasma pretreatment of sugarcane 
bagasse: the influence of biomass particle size in the ozonation process. Appl. Biochem. Biotechnol., 172, 1663-1672.

44. Tamaki, Y. and G. Mazza. 2011. Rapid Determination of Carbohydrates, Ash, and Extractives Contents of Straw Using Attenuated Total Reflectance Fourier Transform Mid-Infrared Spectroscopy. J Agric. Food Chem. 59, 6346-6352.

45. Van Dam, H., Kieboom, A., Van Bekkum, H. 1986. The conversion of fructose and glucose in acidic media: formation of hydroxymethylfurfural. Starch-Stärke, 38, 95-101. ethanol production from sugarcane bagasse based on combined pretreatments and fedbatch enzymatic hydrolysis. Bioresour. Technol. 128, 448-453. 


\section{$577 \quad$ Figure Captions}

578

579 Fig. 1. Instrument set up for the generation of cold air pressure plasma

580 Fig 2. Contour plots exhibiting the interactions of various process parameters on the reducing 581 sugar yield (g/g); (a) interactions between biomass (\% w/v) and time (min); (b) interactions 582 between biomass $(\% \mathrm{w} / \mathrm{v})$ and voltage $(\mathrm{kV})$; (c) interactions between biomass and $\mathrm{H}_{2} \mathrm{SO}_{4}$ 583 concentration $(\%)$; (d) interactions between $\mathrm{FeCl}_{3}$ concentration $(\%)$ and biomass (\% w/v).

584 Fig 3. DSC thermogram of native and plasma pretreated SCW

585 Fig 4. Typical Optical Emission Spectrum (OES) of the dielectric barrier discharge in air $586 \quad($ Operating voltage $=70 \mathrm{kV})$ 


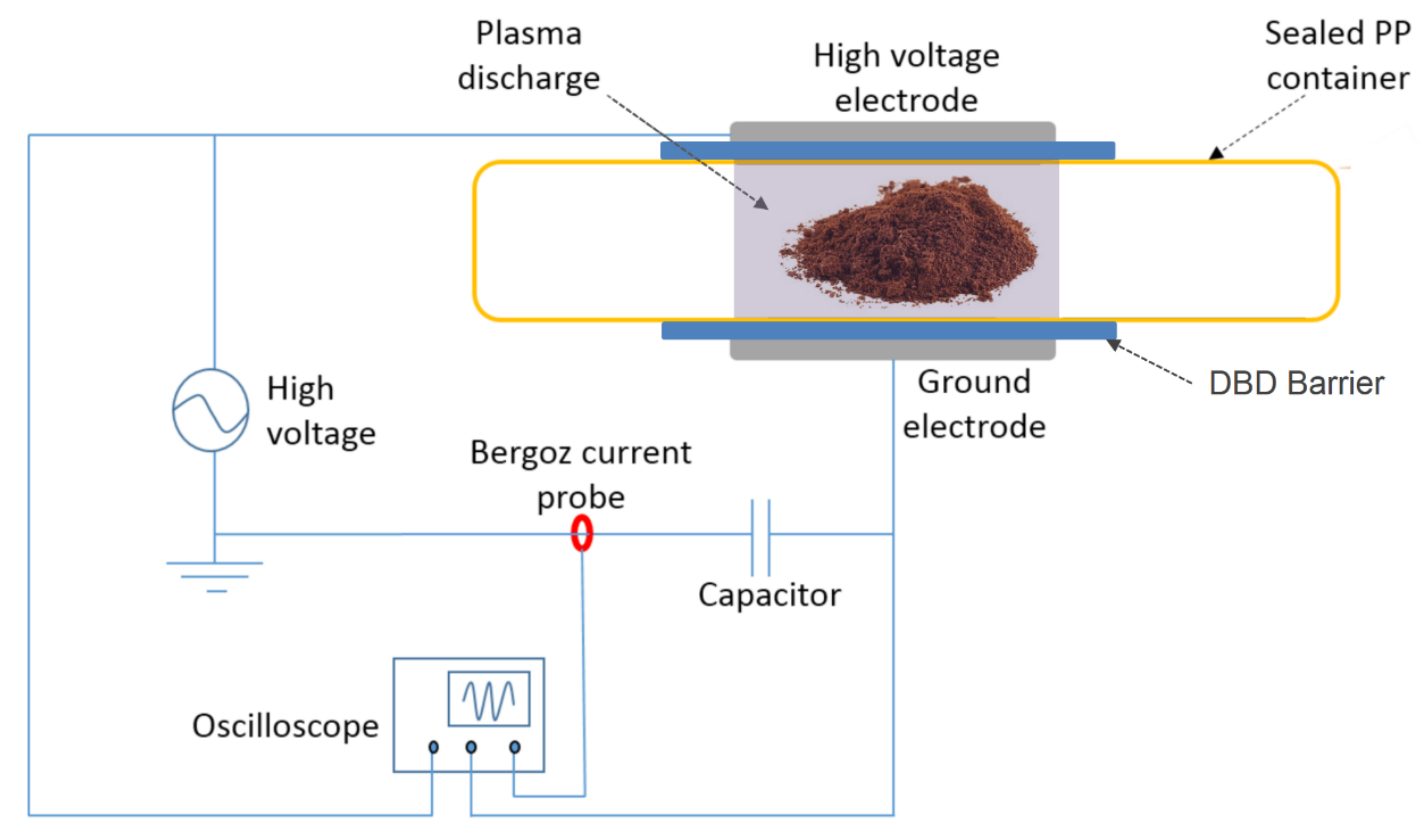



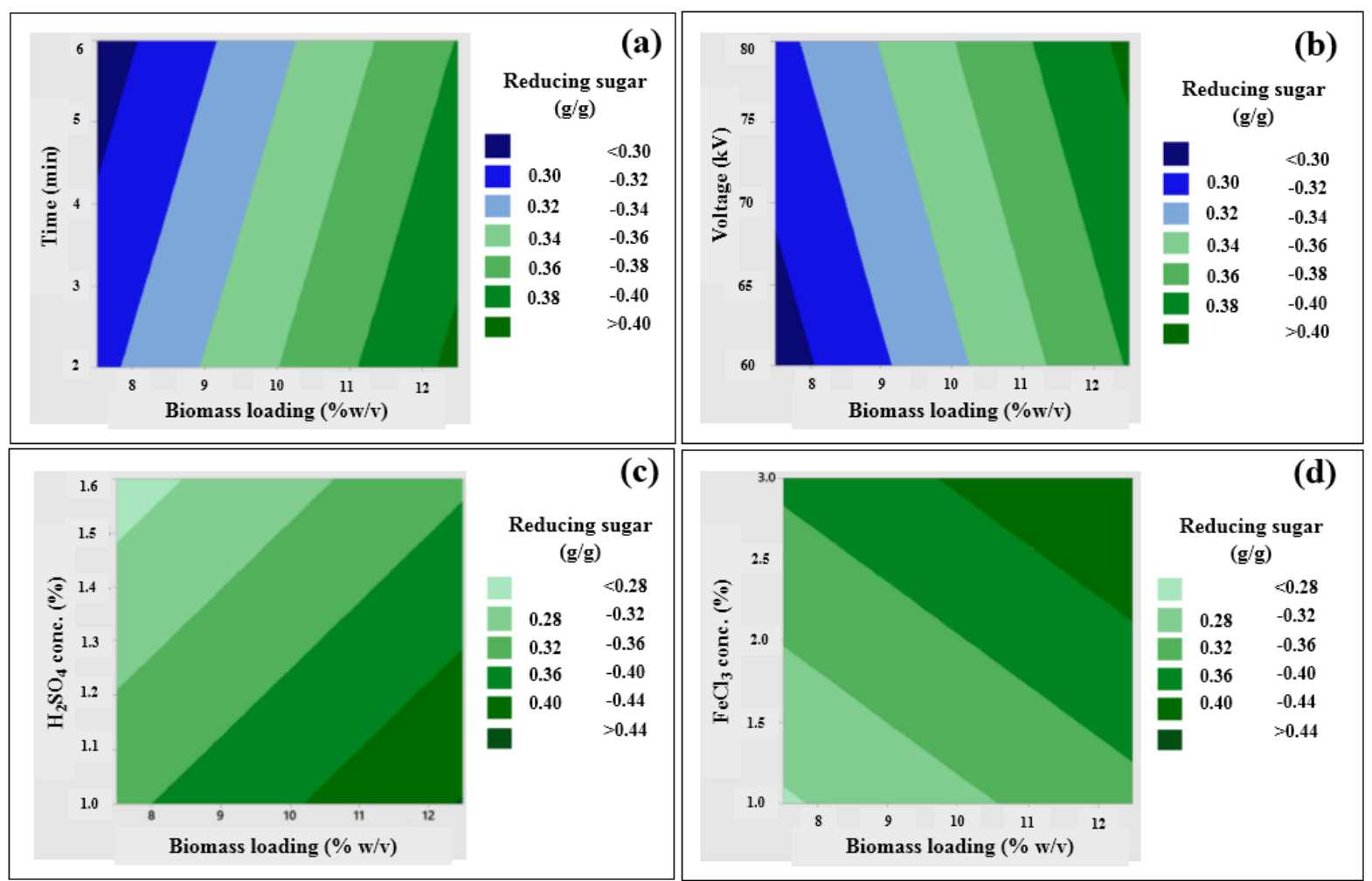

Fig 2. Contour plots exhibiting the interactions of various process parameters on the reducing sugar yield (g/g); (a) interactions between biomass (\% w/v) and time (min); (b) interactions between biomass $(\% \mathrm{w} / \mathrm{v})$ and voltage $(\mathrm{kV})$; (c) interactions between biomass and $\mathrm{H}_{2} \mathrm{SO}_{4}$ concentration (\%); (d) interactions between $\mathrm{FeCl}_{3}$ concentration (\%) and biomass $(\% \mathrm{w} / \mathrm{v})$. 


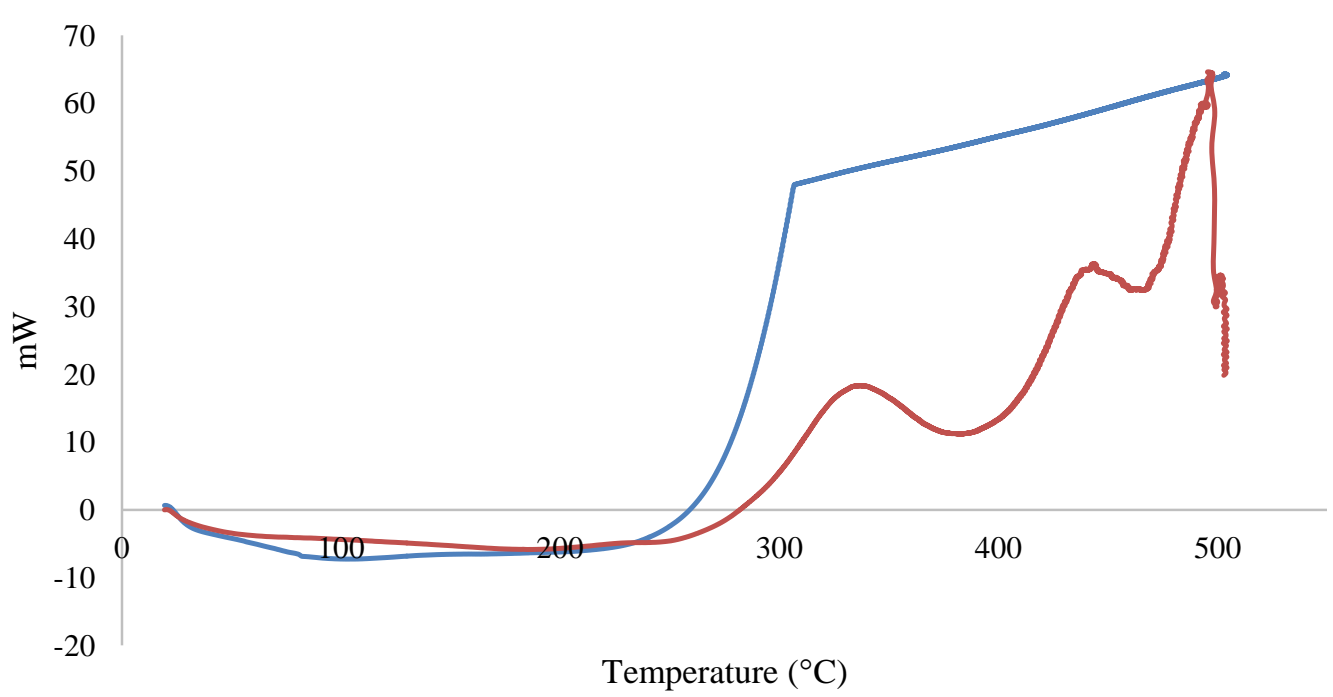

602

- Naive SCW — Pretreated SCW

603

Fig 3. DSC thermogram of native and plasma pretreated SCW

604 


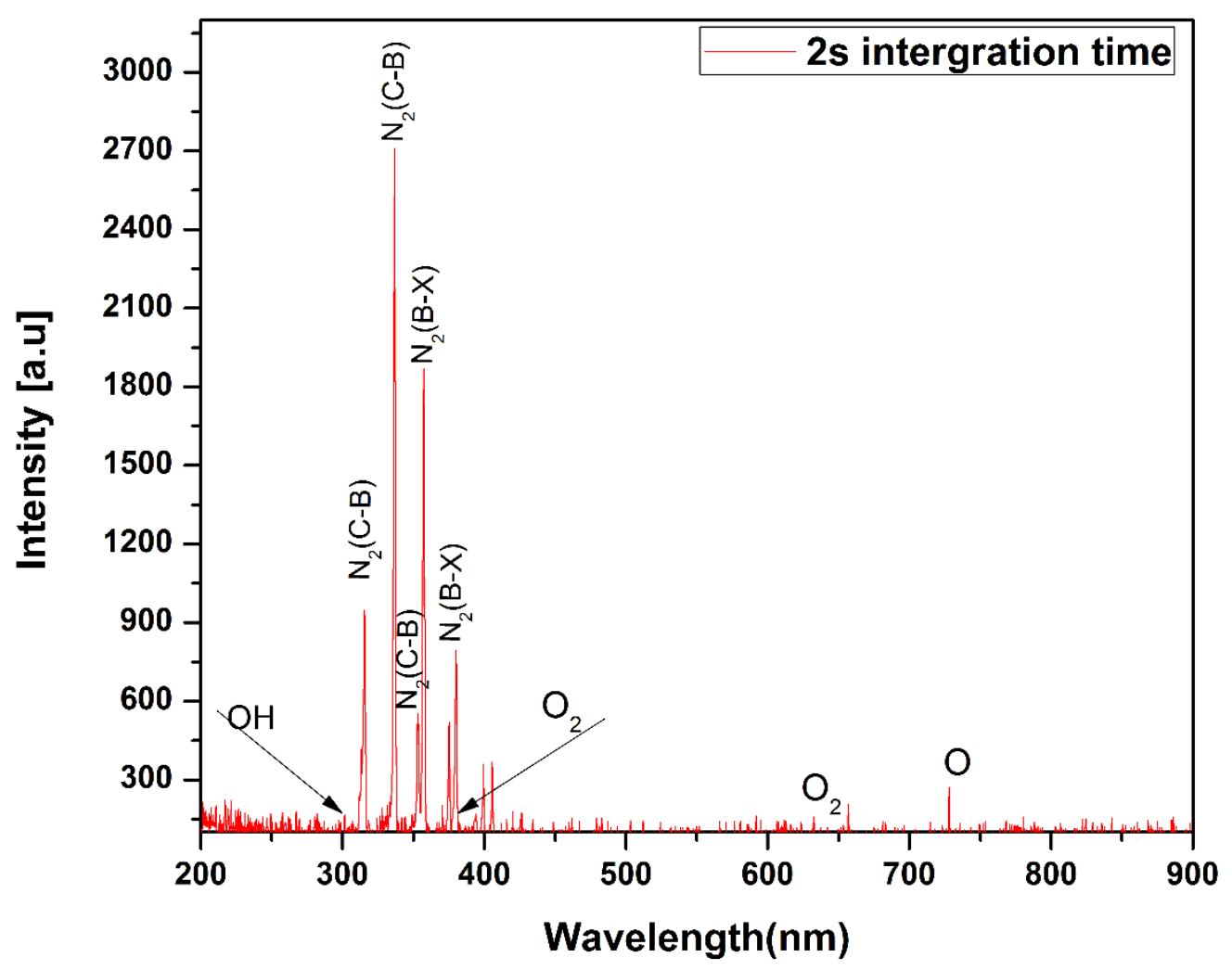

605

606 Fig 4. Typical Optical Emission Spectrum (OES) of the dielectric barrier discharge in air 607 $($ Operating voltage $=70 \mathrm{kV})$

608 
609 Table 1 Taguchi design for optimisation of process parameters involved in plasma 610 pretreatment

\begin{tabular}{|c|c|c|c|c|c|c|}
\hline $\begin{array}{l}\text { Trial } \\
\text { no. }\end{array}$ & $\begin{array}{l}\text { Biomass } \\
\text { loading } \\
(\% \text { w/v })\end{array}$ & $\begin{array}{c}\mathrm{FeCl}_{3} \\
\text { conc. } \\
\%\end{array}$ & $\begin{array}{c}\mathrm{H}_{2} \mathrm{SO}_{4} \\
\text { conc. } \\
\%\end{array}$ & $\begin{array}{l}\text { Time } \\
(\mathbf{m i n})\end{array}$ & $\begin{array}{c}\text { Voltage } \\
(\mathbf{k V})\end{array}$ & $\begin{array}{c}\text { Reducing sugar } \\
(\mathrm{g} / \mathrm{g})\end{array}$ \\
\hline 1 & 7.5 & 1 & 1 & 2 & 60 & 0.299 \\
\hline 2 & 7.5 & 1 & 1 & 2 & 70 & 0.311 \\
\hline 3 & 7.5 & 1 & 1 & 2 & 80 & 0.317 \\
\hline 4 & 7.5 & 2 & 1.4 & 4 & 60 & 0.296 \\
\hline 5 & 7.5 & 2 & 1.4 & 4 & 70 & 0.302 \\
\hline 6 & 7.5 & 2 & 1.4 & 4 & 80 & 0.311 \\
\hline 7 & 7.5 & 3 & 1.6 & 6 & 60 & 0.300 \\
\hline 8 & 7.5 & 3 & 1.6 & 6 & 70 & 0.313 \\
\hline 9 & 7.5 & 3 & 1.6 & 6 & 80 & 0.318 \\
\hline 10 & 10 & 1 & 1.4 & 6 & 60 & 0.253 \\
\hline 11 & 10 & 1 & 1.4 & 6 & 70 & 0.264 \\
\hline 12 & 10 & 1 & 1.4 & 6 & 80 & 0.272 \\
\hline 13 & 10 & 2 & 1.6 & 2 & 60 & 0.309 \\
\hline 14 & 10 & 2 & 1.6 & 2 & 70 & 0.309 \\
\hline 15 & 10 & 2 & 1.6 & 2 & 80 & 0.321 \\
\hline 16 & 10 & 3 & 1 & 4 & 60 & 0.413 \\
\hline 17 & 10 & 3 & 1 & 4 & 70 & 0.428 \\
\hline 18 & 10 & 3 & 1 & 4 & 80 & 0.455 \\
\hline 19 & 12.5 & 1 & 1.6 & 4 & 60 & 0.269 \\
\hline 20 & 12.5 & 1 & 1.6 & 4 & 70 & 0.296 \\
\hline 21 & 12.5 & 1 & 1.6 & 4 & 80 & 0.300 \\
\hline 22 & 12.5 & 2 & 1 & 6 & 60 & 0.428 \\
\hline 23 & 12.5 & 2 & 1 & 6 & 70 & 0.452 \\
\hline 24 & 12.5 & 2 & 1 & 6 & 80 & 0.446 \\
\hline 25 & 12.5 & 3 & 1.4 & 2 & 60 & 0.432 \\
\hline 26 & 12.5 & 3 & 1.4 & 2 & 70 & 0.493 \\
\hline 27 & 12.5 & 3 & 1.4 & 2 & 80 & 0.474 \\
\hline
\end{tabular}

611

612

613

614

615

616

617

618 
622 Table 2 Analysis of variance data for reducing sugar yield after plasma pretreatment

\begin{tabular}{lccccc}
\hline \multicolumn{1}{c}{ Source } & DF & Adj SS & Adj MS & $\begin{array}{c}\text { F- } \\
\text { Value }\end{array}$ & $\begin{array}{c}\text { P- } \\
\text { Value }\end{array}$ \\
\hline Biomass & 1 & 0.037545 & 0.003833 & 113.04 & 0.019 \\
loading & 1 & 0.060517 & 0.0061759 & 151.2 & 0.006 \\
$\mathrm{FeCl}_{3}$ & 1 & 0.036434 & 0.0037195 & 244.84 & 0.014 \\
$\mathrm{H}_{2} \mathrm{SO}_{4}$ & 1 & 0.002668 & 0.002723 & 147.41 & 0.007 \\
Time & 1 & 0.00254 & 0.002596 & 89.95 & 0.06 \\
Voltage & 1 & 0.005191 & 0.000687 & 54.83 & 0.065 \\
Error & 6 & 0.144895 & & & \\
Total & & & & &
\end{tabular}

$\mathrm{R}-$ R$\mathrm{sq}=96.42 \% \quad \mathrm{sq}(\mathrm{adj})=95.56 \%$ 
628 - A novel $\mathrm{FeCl}_{3}$ assisted plasma pretreatment strategy was proposed for lignocellulose.

629 - Extensive delignification in spent coffee waste was achieved upon pretreatment.

630 - The polysaccharide fraction of spent coffee grounds was left unaffected.

631 - High reducing sugar yield was obtained upon hydrolysis of pretreated spent coffee waste.

632 - Pretreated SCW was found to be a suitable substrate for bioethanol production.

633 